\title{
Physiologic Effects of 3 Different Neonatal Volume-Targeted Ventilation Modes in Surfactant-Deficient Juvenile Rabbits
}

\author{
Robert M DiBlasi, Christine N Kearney, Justin C Hotz, John W Salyer, Jonathan A Poli, \\ Dave N Crotwell, and Silvia M Hartmann
}

\begin{abstract}
BACKGROUND: Different brands of volume-targeted modes may vary the location of tidal volume $\left(V_{T}\right)$ monitoring and whether peak inspiratory pressure is adjusted based on inspiratory, expiratory, or leak-compensated $V_{T}$. These variables may result in different levels of support provided to patients, especially when an endotracheal tube (ETT) leak is present. We hypothesized that there would be no differences in gas exchange, triggering, or work of breathing between volume-targeted modes of 3 different brands of equipment in a surfactant-deficient, spontaneously breathing animal model with and without an ETT leak. METHODS: Twelve rabbits (mean \pm SD $1.61 \pm 0.20 \mathrm{~kg}$ ) were sedated, anesthetized, intubated, lavaged with $0.9 \%$ saline solution, and randomized in a crossover design so that each animal was supported by 3 different volume-targeted modes at identical settings with and without an ETT leak. After $30 \mathrm{~min}$, arterial blood gas, $\mathrm{V}_{\mathrm{T}}$, and esophageal and airway pressure were recorded for each condition, and pressure-rate product and percentage of successfully triggered breaths were calculated. RESULTS: Gas exchange and the pressure-rate product were not different between the ventilators in the absence of an ETT leak. When an ETT leak was introduced, volume-guarantee modes allowed a higher percentage of triggered breaths and peak inspiratory pressure, which resulted in higher minute ventilation, $\mathrm{pH}$, and lower $\mathrm{P}_{\mathrm{aCO}}$ than the pressure-regulated volume control mode $(P<.05)$. CONCLUSIONS: When a moderate ETT leak was present, volume-targeted modes that used proximal $V_{T}$ monitoring and triggering with adaptive leak compensation capabilities appeared more effective in providing ventilation support than did a ventilator that used measurements obtained from the back at the ventilator and does not have leak compensation. Key words: animal model; endotracheal tube leak; neonatal; ventilator; volume-guarantee mode; volume-targeted ventilation. [Respir Care 2019;64(4):361-371. ( 2019 Daedalus Enterprises]
\end{abstract}

\section{Introduction}

Volume-targeted ventilation is a time-cycled, pressure control mode that functions to achieve a goal set tidal volume $\left(\mathrm{V}_{\mathrm{T}}\right)$ by adjusting peak inspiratory pressure (PIP) on an ongoing basis. PIP adjustment is dependent on changes in monitored $\mathrm{V}_{\mathrm{T}}$, respiratory compliance and re-

Mr DiBlasi, Ms Kearney, Mr Salyer, Mr Poli, and Mr Crotwell are affiliated with the Seattle Children's Hospital and Research Institute, Seattle, Washington. Mr Hotz is affiliated with the Children's Hospital of Los Angeles, Los Angeles, California. Dr Hartmann is affiliated with the University of Washington School of Medicine, Seattle, Washington.

This study was funded with support from Draeger (Telford, Pennsylvania). sistance, and patient effort. There are several proposed advantages of volume-targeted ventilation over pressure control ventilation in neonates, which include: controlled minute ventilation to avoid hypercarbia and hypocarbia, reduction in ventilator-induced lung injury with changes in lung compliance, a lower risk of lung de-recruitment as-

\footnotetext{
Mr DiBlasi discloses relationships with Draeger, Aerogen Pharma, Mallinckrodt Medical, Vero Biopharma, Chiesi, Neotech, and Vapotherm. The remaining authors have disclosed no conflicts of interest.
}

Correspondence: Robert M DiBlasi RRT RRT-NPS FAARC, Seattle Children's Hospital and Research Institute, 1900 Ninth Ave North, Seattle, WA 98101. E-mail: robert.diblasi@ seattlechildrens.org.

DOI: $10.4187 /$ respcare.06271 


\section{Volume-TARgeted Ventilation IN RABbits}

sociated with variable respiratory drive in neonates, reduced work of breathing, and automatic weaning of ventilator settings. ${ }^{1}$ A 2017 Cochrane meta-analysis of 20 randomized controlled trials, including 16 parallel trials ( $n=977$ infants) and 4 crossover trials ( $n=88$ infants), showed benefit of volume-targeted modes compared with pressure control ventilation in pre-term neonates. ${ }^{2}$ In this meta-analysis, infants supported with volume-targeted modes had a lower incidence in combined outcome of death or chronic lung disease, hypocarbia, pneumothorax, mean days of ventilation, and combined outcome of periventricular leukomalacia or grade III/IV intraventricular hemorrhages. ${ }^{2}$

\section{See the Related Editorial on Page 484}

Despite the positive findings in the Cochrane review, ${ }^{2}$ widespread acceptance and implementation of volume-targeted ventilation has been slow in the neonatal ICU setting. One survey, of 50 international tertiary center neonatal ICUs, showed that only $25 \%$ of the centers used volume-targeted ventilation. ${ }^{3}$ The leading reasons for continued use of pressure control ventilation, at the time of this publication (2011), were cited as "good outcomes with current ventilator strategy" and "insufficient evidence for the benefit of volume-targeted ventilation in neonatal ICU patients."

In addition, differences in ventilator performance related to accuracy and the location of volume monitoring and flow triggering, ability to appropriately target $\mathrm{V}_{\mathrm{T}}$ and pressure when endotracheal tube (ETT) leaks are present, complexity in the mode operation, and lack of standardized protocols may help explain low clinical use of volume-targeted ventilation. ${ }^{1}$ Recently, there have been significant improvements in ventilators that may address the specific needs of neonates. Some of these features include improved accuracy in $\mathrm{V}_{\mathrm{T}}$ measurement, flow-sensor technology, rapid signal processing, adaptive leak compensation algorithms for triggering and volume targeting, and the ability to adjust PIP to target significantly smaller $V_{T}$ $(\sim 2 \mathrm{~mL})$. These proposed improvements may have important clinical implications for low birthweight infants that require invasive ventilation.

The ability to provide consistent and accurate $\mathrm{V}_{\mathrm{T}}$ and triggering has recently been evaluated across different volume-targeted modes and ventilator brands by using neonatal lung simulators with simulated ETT leaks. ${ }^{4}$ However, there is a lack of data from human and animal studies to indicate whether volume-targeted mode performance of different ventilator brands has any effect on physiologic outcomes. We hypothesized that there would be no differences in ventilation parameters, gas exchange, triggering, or effort of breathing in surfactant-deficient, lung-injured,

\section{QUICK LOOK}

\section{Current knowledge}

A recent meta-analysis showed that volume-targeted modes of ventilation may improve outcomes when compared with pressure control modes in premature infants. Differences in performance among the different brands of volume-targeted ventilation modes were shown in artificial lung models adapted with simulated endotracheal tube (ETT) leaks, but it was unclear whether these differences may have any physiologic impact on gas exchange or work of breathing.

\section{What this paper contributes to our knowledge}

In surfactant-deficient, spontaneously breathing rabbits, aside from triggering and minute ventilation, 3 commonly used ventilators provided similar lung support without an ETT leak. When a moderate ETT leak was present, volume-targeted modes that use proximal triggering and volume monitoring with adaptive leak compensation capabilities seemed more effective in providing ventilation support than did a ventilator that uses measurements obtained from the expiratory limb of the ventilator and does not have leak compensation.

spontaneously breathing juvenile rabbits with and without an ETT leak among 3 different volume-targeted modes that monitor $\mathrm{V}_{\mathrm{T}}$ at different locations and regulate PIP based on inspiratory, expiratory, or leak adapted (compensated) $\mathrm{V}_{\mathrm{T}}$.

\section{Methods}

This study was funded with a grant from Dräger (Telford, Pennsylvania). The study was designed, measurements obtained, data reduced, and manuscript written by the investigators, with no input from the grantor. We evaluated 3 different commonly used ventilators that have neonatal-specific volume-targeted modes: Servo-i (Maquet, Solna, Sweden), AVEA (CareFusion, Yorba Linda, California), and Babylog VN500 (Dräger Medical, Lubeck, Germany). Ventilator brand selection was based on differences in volume-targeted mode operation, specifically, as they relate to (1) location of $\mathrm{V}_{\mathrm{T}}$ monitoring and breath triggering, (2) ability to stabilize pressure in the expiratory phase in the presence of a leak, and (3) differences in $\mathrm{V}_{\mathrm{T}}$ input required for PIP adjustment. The different triggering locations, $\mathrm{V}_{\mathrm{T}}$ measurement inputs, and leak compensation variables related to the specific brand of volume-targeted modes are shown in Table 1.

Under an institutionally approved animal studies protocol, 12 juvenile female New Zealand White rabbits (Western 
Oregon Rabbit Company, Philomath, Oregon), that weighed (mean $\pm \mathrm{SD}) 1.61 \pm 0.20 \mathrm{~kg}$, were tranquilized with $1 \mathrm{mg} / \mathrm{kg}$ acepromazine and anesthetized with $33 \mathrm{mg} / \mathrm{kg}$ ketamine and $6.6 \mathrm{mg} / \mathrm{kg}$ intramuscular xylazine. The neck and upper chest were shaved. Cetacaine spray $(0.1 \%)$ was applied topically to the oral pharynx and glottis to reduce gag reflex and laryngospasm during oral intubation. Local anesthesia was provided around the trachea with lidocaine before tracheal isolation and oral intubation. The trachea was dissected, isolated, and intubated with a $2.5-\mathrm{mm}$ inner diameter ETT under direct laryngoscopy. After intubation, a strand of umbilical tape was used to anchor the trachea and the ETT, to prevent displacement, gas leakage, and saline solution leakage during lavage, and to allow investigators the ability to control the magnitude of the ETT leak. Auscultation of bilateral breath sounds and the presence of end-tidal $\mathrm{CO}_{2}\left(\mathrm{P}_{\mathrm{ETCO}_{2}}\right)$ confirmed proper ETT placement.

Each animal was initially stabilized and ventilated with pressure-continuous mandatory ventilation (BabyLog VN500): 40 breaths/min, $0.30 \mathrm{~s}$ inspiratory time, and $5 \mathrm{~cm} \mathrm{H}_{2} \mathrm{O}$ PEEP. The PIP level was adjusted for a $\mathrm{V}_{\mathrm{T}}$ of $6.5 \mathrm{~mL} / \mathrm{kg}$. We chose $6.5 \mathrm{~mL} / \mathrm{kg} \mathrm{V}$ to reduce any deleterious effects that may have been created by dead space from the research pneumotachometer $(\sim 1 \mathrm{~mL})$. The $\mathrm{P}_{\mathrm{ETCO}_{2}}$ levels were monitored, and ventilator frequencies were adjusted to maintain $\mathrm{P}_{\mathrm{ETCO}_{2}}$ between 40 and $50 \mathrm{~mm} \mathrm{Hg}$. $\mathrm{S}_{\mathrm{pO}_{2}}$ was monitored ( $\mathrm{Rad} 7$, Masimo, Irvine, California) with a tail probe, and body temperature was monitored continuously with a rectal temperature probe and maintained normothermic $\left(38-39^{\circ} \mathrm{C}\right)$ by using a warming pad. A 20 gauge angiocatheter was placed in the right jugular vein for administration of fluids and medications. Sedation and analgesia were maintained to minimize pain and promote spontaneous breathing by using continuous intravenous infusion of ketamine and xylazine ( 3 and $0.18 \mathrm{mg} / \mathrm{kg} / \mathrm{h}$, respectively) and titrated based on blood pressure, heart rate, and maintenance of the anesthetic plane. Maintenance intravenous fluids were provided with continuous infusion at $3 \mathrm{~mL} / \mathrm{kg} / \mathrm{h}$ of $0.9 \%$ saline solution that contained 5\% dextrose. A 22-gauge angiocatheter was placed in the right carotid artery for heart rate and blood pressure monitoring and sampling for blood-gas analyses.

The $\mathrm{F}_{\mathrm{IO}_{2}}$ was increased to 1.0 , and the lungs were lavaged with $25 \mathrm{~mL} / \mathrm{kg}$ of warmed normal $(0.9 \%)$ saline solution $\left(39^{\circ} \mathrm{C}\right)$ to induce surfactant deficiency, with 5-min recoveries between lavages until dynamic compliance was $50 \%$ of the non-lavaged value and $\mathrm{P}_{\mathrm{aO}_{2}}$ of $<70 \mathrm{~mm} \mathrm{Hg}$ on an $\mathrm{F}_{\mathrm{IO}_{2}}$ of 0.5 . The animals were allowed to stabilize for 30 min. $\mathrm{F}_{\mathrm{IO}_{2}}$ was adjusted to keep $\mathrm{S}_{\mathrm{pO}_{2}}$ between 90 and $92 \%$. The $\mathrm{P}_{\mathrm{ETCO}}$ monitor was removed and a Hans Rudolph (Shawnee, Kansas) calibrated differential pressure pneumotachometer was placed in series for flow, $\mathrm{V}_{\mathrm{T}}$, and airway pressure measurements. Pressures were measured by 


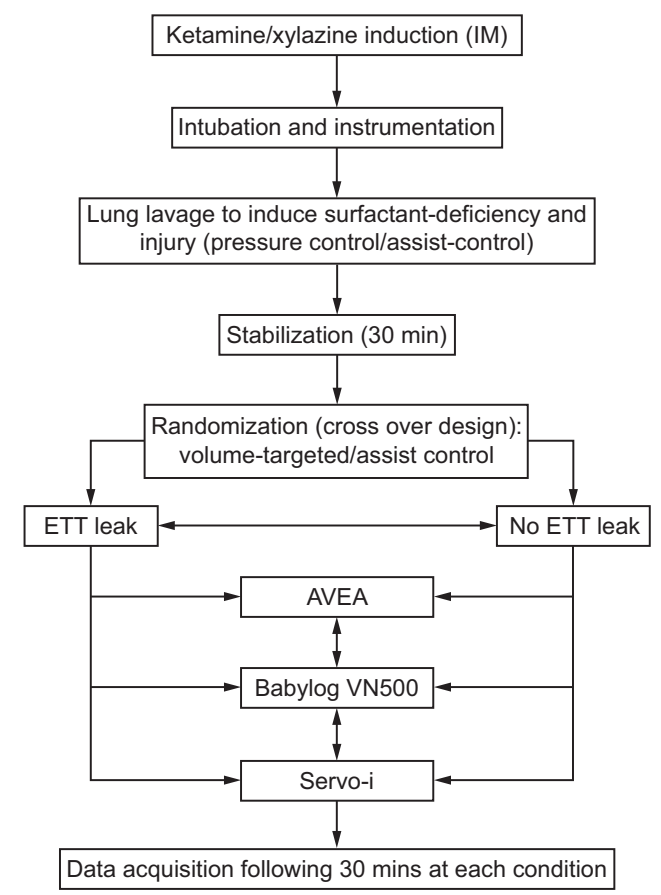

Fig. 1. Diagram of experimental procedures and testing conditions with each of the ventilator's volume-targeted modes. IM = intramuscular.

using calibrated pressure transducers (XRA515GN, Honeywell, Morristown, New Jersey), and data were recorded on a desktop computer. A 6 French esophageal balloon catheter (Cardinal Healthcare, Dublin, Ohio) was positioned in the lower esophagus, and proper placement was confirmed by using the occlusion technique. ${ }^{5}$ Changes in esophageal pressure were used to estimate changes in pleural pressures and were used in the calculations of pressurerate product and triggered breaths $(\%)$. All the ventilators were equipped with standard neonatal ventilator circuits (Evaqua II, Fisher \& Paykel, Auckland, New Zealand) and heated humidifier systems (MR 850, Fisher \& Paykel). A ventilator circuit leak test and a circuit calibration were performed per manufacturer's recommendation. Proprietary proximal flow sensors were used for each of the different ventilators. Ventilators were configured to display measured $\mathrm{V}_{\mathrm{T}}$ based on a body temperature pressure saturated condition calculation.

The spontaneously breathing, surfactant-deficient animals served as their own controls and were supported in a randomized crossover block sequence so that each animal was supported with and without an ETT leak by using each of the 3 ventilator's volume-targeted assist-control modes for $30 \mathrm{~min}$. They were supported at identical $\mathrm{V}_{\mathrm{T}}$ settings and at the same $\mathrm{F}_{\mathrm{IO}_{2}}$, inspiratory time, PEEP, and breathing frequency as those established with pressure control. A schematic of the animal procedures and experimental conditions is shown in Figure 1. The flow or pressure trigger setting was carefully adjusted with the most-sensitive triggering setting that allowed the animals' ability to optimize ventilator triggering based on intrinsic efforts without creating an autocycling condition (confirmed by esophageal monitoring). The high-pressure limit on each ventilator was adjusted to $30 \mathrm{~cm} \mathrm{H}_{2} \mathrm{O}$ to ensure $\mathrm{V}_{\mathrm{T}}$ delivery in the presence of an ETT leak.

The ETT leak condition was controlled between each of the 30-min testing epochs by placing rabbits back into pressure control with assist/control mode on the Dräger Babylog VN500. The umbilical tape was loosened to allow gas to exit to the atmosphere via upper airways to achieve a $50 \%$ inspiratory leak (calculated as $100 \%$ [inspiratory minute volume - expiratory minute volume]/inspiratory minute volume) at a PIP of $20 \mathrm{~cm} \mathrm{H}_{2} \mathrm{O}$ for $5 \mathrm{~min}$. For the non-leak condition, the umbilical tape was tied so that the tracheal wall was occluded against the ETT, and $0 \%$ leak was maintained for $5 \mathrm{~min}$ before being supported with the different volume-targeted modes.

Blood gas measurements were obtained and blood pressure, heart rate, airway pressure, flow, and esophageal pressure were recorded for $45 \mathrm{~s}$ at $1040 \mathrm{~Hz}$ after $30 \mathrm{~min}$ of support with each ventilator and leak condition in all the animals. Ventilation settings and measured parameters were also obtained at this time. We processed physiologic measurements (flow, $\mathrm{V}_{\mathrm{T}}$, PIP, and esophageal pressure) by using Vivo Sense software (Vivonetics, San Diego, California) and obtained mean values for $\mathrm{V}_{\mathrm{T}}$, PIP, airway pressure, PEEP, and the pressure-rate product for each recording after removing artifacts. The pressure-rate product is the peak-to-trough change in esophageal pressure $\left(\mathrm{cm} \mathrm{H}_{2} \mathrm{O}\right) \times$ breathing frequency (breaths/min) and is a surrogate for effort of breathing. ${ }^{6-11}$ All measured pressure-rate products were attributable to the animal, and further subdivision of animal versus ventilator effort was not required. Triggered breaths (\%) were calculated as the total number of animal-initiated respiratory efforts to the total number of corresponding breaths triggered on the ventilator. ${ }^{12}$ The minute ventilation calculation was based on $\mathrm{V}_{\mathrm{T}}$, breathing frequency, and proportion of triggered efforts that resulted in ventilator-supported breaths.

\section{Statistical Analysis}

Data, as mean $\pm \mathrm{SD}$, were calculated for all continuous outcome variables (eg, vital signs, pressure-rate product, PIP, $\mathrm{CO}_{2}$ levels) according to ventilator brand and leak status. We compared differences in mean variables between ventilator brands for the ETT leak and no ETT leak conditions independently. We then compared differences within the individual ventilator brand to assess differences between the leak and no leak conditions. Frequencies and percentages were calculated for ventilator and leak assignment to assess data completeness. A linear-mixed effects 
model, an extension of 2-way analysis of variance that accounts for the repeated measures taken on the rabbits, was used to evaluate the association of ventilator and leak status on each continuous outcome variable. ${ }^{13}$

In these linear mixed-effects models, ventilator type, and leak status were treated as fixed effects. A compound symmetric covariance matrix was used in this model, which assumes that the correlation between measurements was equal for any 2 measurements taken on the same rabbit. All models were assessed for convergence, and the modeling assumptions of homogeneity of variance and normality were verified by using 2 residual diagnostics: residuals versus predicted values and normal probability plots. Differences in outcome variables for each ventilator and leak status were estimated from the model. Bonferroni correction was used to adjust for multiple comparisons. Significance testing was done at the $\alpha=0.05$ level. SAS 9.4 (SAS Institute, Cary, North Carolina) was used for all the analyses.

\section{Results}

\section{Animals}

The rabbits weighed (mean $\pm \mathrm{SD}$ ) $1.61 \pm 0.20 \mathrm{~kg}$. After saline solution lavage, lung compliance decreased from $1.30 \pm 0.32$ to (mean $\pm \mathrm{SD}$ ) $0.62 \pm 0.10 \mathrm{~mL} / \mathrm{cm} \mathrm{H}_{2} \mathrm{O}$ $(P=.001)$, which was well within the specified target for reducing compliance by $\sim 50 \%$ after lavage. This result was achieved with (mean $\pm \mathrm{SD}$ ) $10.63 \pm 1.21$ (range, 9-13) lavages per animal. Heart and blood pressure were not different among the different ventilator modes or leak conditions.

\section{Ventilation Parameters}

The delivered PIP was not different among the 3 ventilators in the absence of an ETT leak. The PIP increased with the introduction of an ETT leak with the AVEA $(P=$ $.004)$ and Babylog VN500 $(P=.01)$ ventilators $(\sim 6$ and $4 \mathrm{~cm} \mathrm{H}_{2} \mathrm{O}$, respectively) (Table 2). In contrast, the PIP decreased with the Servo-i $\left(P=.01, \sim 4 \mathrm{~cm} \mathrm{H}_{2} \mathrm{O}\right)$ and was lower than the other ventilators in the presence of an ETT leak $(P<.05)$. The AVEA had a higher mean airway pressure between leak and no leak conditions $(P=.02)$ and was lower than the Babylog VN500 without a leak $(P=.03)$. The Servo-i had higher delivered $\mathrm{V}_{\mathrm{T}}$ than the AVEA without a leak $(P=.03)$ and lower $\mathrm{V}_{\mathrm{T}}$ than the Babylog VN500 when an ETT leak was present $(P=.03)$. The AVEA had a $13 \%$ higher $\mathrm{V}_{\mathrm{T}}$ delivery with than without a leak $(P=.002)$; whereas the $\mathrm{V}_{\mathrm{T}}$ was $19 \%$ lower with the Servo-i $(P=.001)$ (Table 2). The Dräger VN500 was the only ventilator to have measured $\mathrm{V}_{\mathrm{T}}$ accuracy (\% error) (Table 2) within 5\% of the pre-set value for both leak

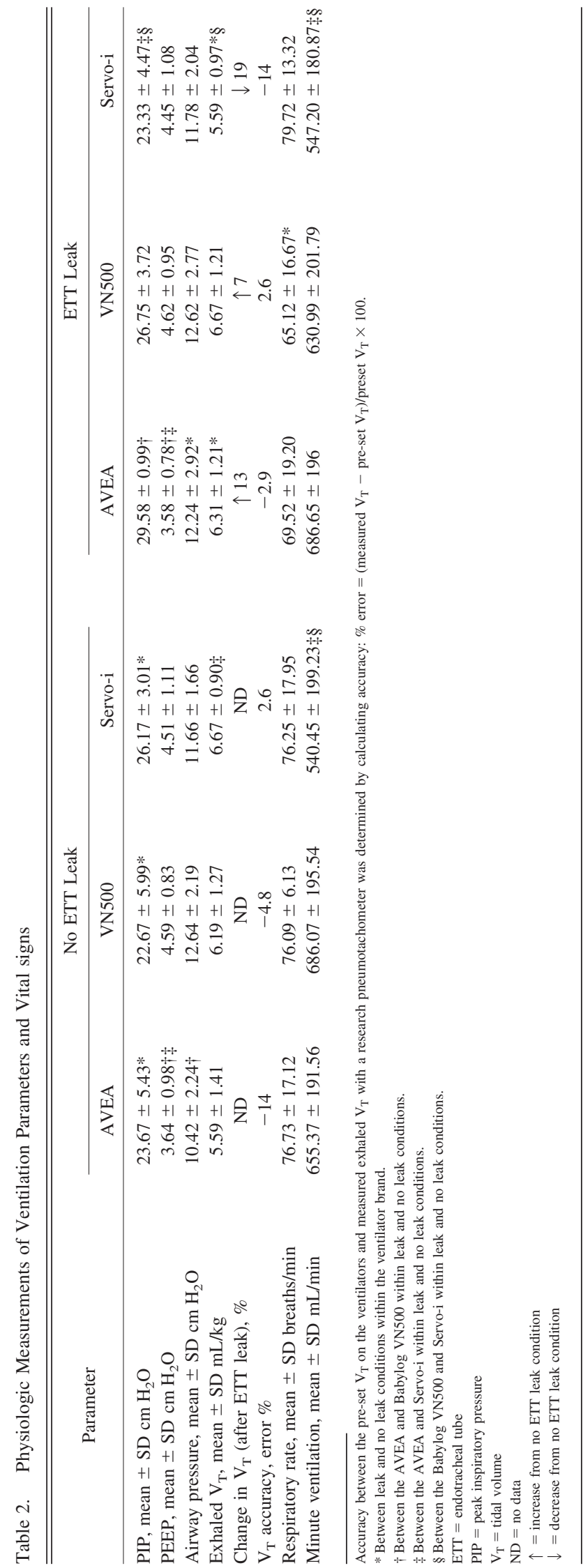




\section{Volume-TARgETED Ventilation IN RABBits}
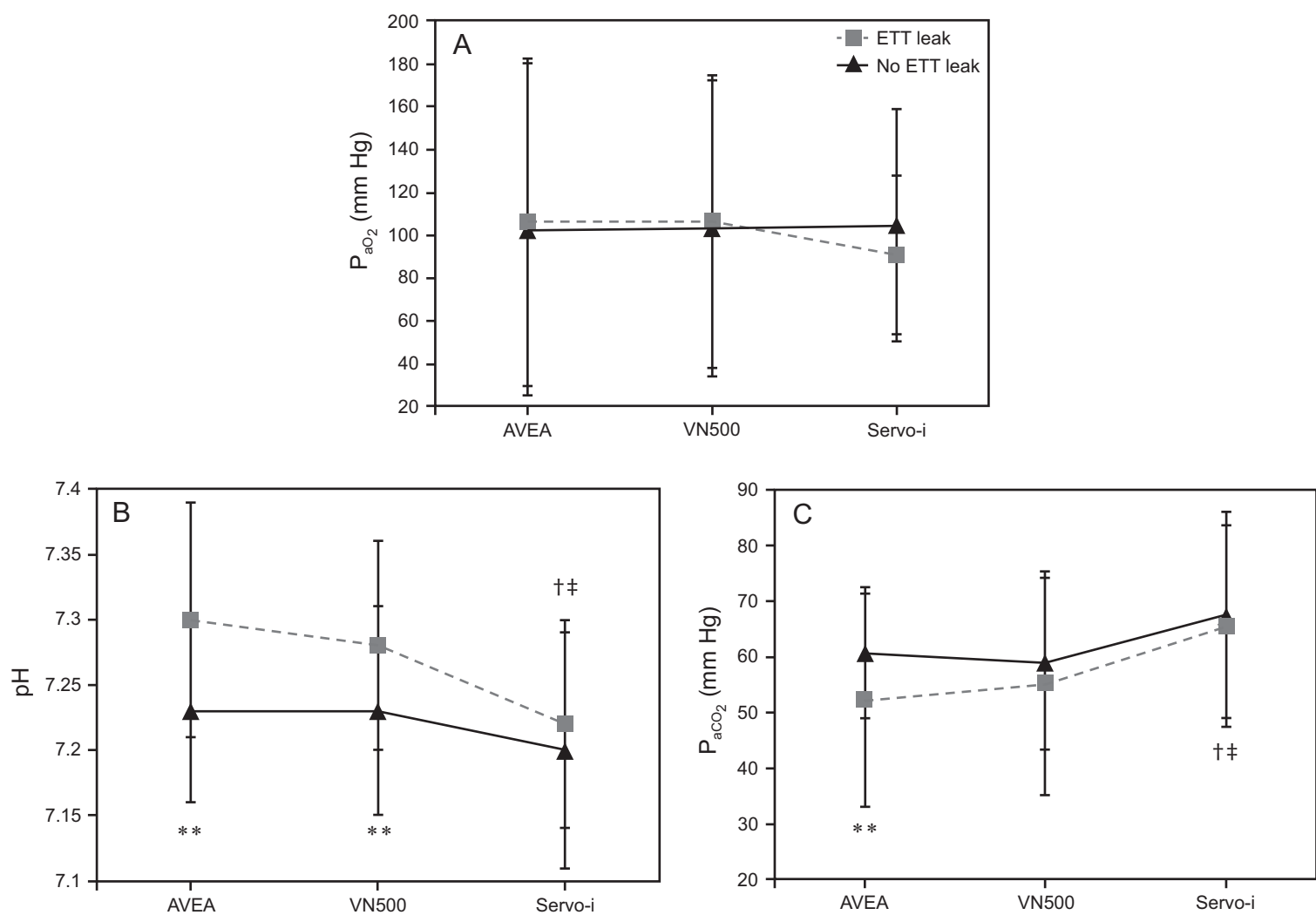

Fig. 2. Effect of each ventilator's volume-targeted mode with and without ETT leak on gas exchange: $P_{a O_{2}}(A), p H(B)$, and $P_{a c O}(C)$. Data are presented as mean \pm SD. Linear-mixed effects models were used to evaluate the association of ventilator and leak status on each continuous outcome variable with ventilator type and leak status treated as fixed effects; $P<.05$ was considered significant: * $P<.05$ between the AVEA and Babylog VN500 within leak and no leak conditions; $\uparrow P<.05$ between the AVEA and Servo-i within leak and no leak conditions; $¥ P<.05$ between the Babylog VN500 and Servo-i within leak and no leak conditions; ${ }^{* *} P<.05$ between leak and no leak conditions within the ventilator brand.

and no leak conditions. There were no differences in breathing frequency between the different modes during the no leak condition, but the breathing frequency was lower during ETT leak conditions with the Babylog VN500 $(P<.05)$. The minute ventilation was lower with the Servo-i than with the other 2 ventilators within both leak conditions $(P<.05)$.

\section{Oxygenation and Ventilation}

There were no differences in $\mathrm{P}_{\mathrm{aO}_{2}}$ among the different volume-targeted modes under no leak and ETT leak conditions (Fig. 2A). When no leak was present, $\mathrm{P}_{\mathrm{aCO}}$ was not different among the 3 ventilator brands. However, when an ETT leak was introduced, the AVEA $(P=.009)$ and Baby$\log \mathrm{VN500}(P=.047)$ had lower $\mathrm{P}_{\mathrm{aCO}_{2}}$ and higher $\mathrm{pH}(P=$ $.001)$ than the Servo-i $(P<.05)$ (Fig. 2, B and C). The AVEA had lower $\mathrm{P}_{\mathrm{aCO}_{2}}(P=.02)$ and the AVEA and Baby$\log$ VN500 $(P=.001)$ had higher $\mathrm{pH}(P=.003)$ between the ETT leak and non-leak ETT conditions (Fig. 2B).

\section{Effort of Breathing and Triggering}

The pressure-rate product measurements were similar among all 3 ventilators when there was no ETT leak (Fig. 3A). When an ETT leak was introduced, the pressure-rate product decreased significantly when animals were ventilated with the AVEA $(P=.01)$ and Babylog VN500 $(P=.006)$. There was no difference in the pressure-rate product between the leak and no leak conditions when using the Servo-i ventilator. The Babylog VN500 had a lower pressure-rate product than the Servo-i when an ETT leak was present $(P=.042)$. There were no differences in triggered breaths between the AVEA and Babylog VN500 ventilators, with both ventilators having $>90 \%$ triggered breaths under each of the leak conditions. The Servo-i had fewer successfully triggered breaths than the other 2 ventilators, regardless of leak condition $(P<.05)$ (Fig. 3B). Approximately $67 \%$ of breaths were successfully triggered by the animals while on the Servo-i ventilator when there was no leak. This increased to $\sim 78 \%$ when a leak was introduced. 

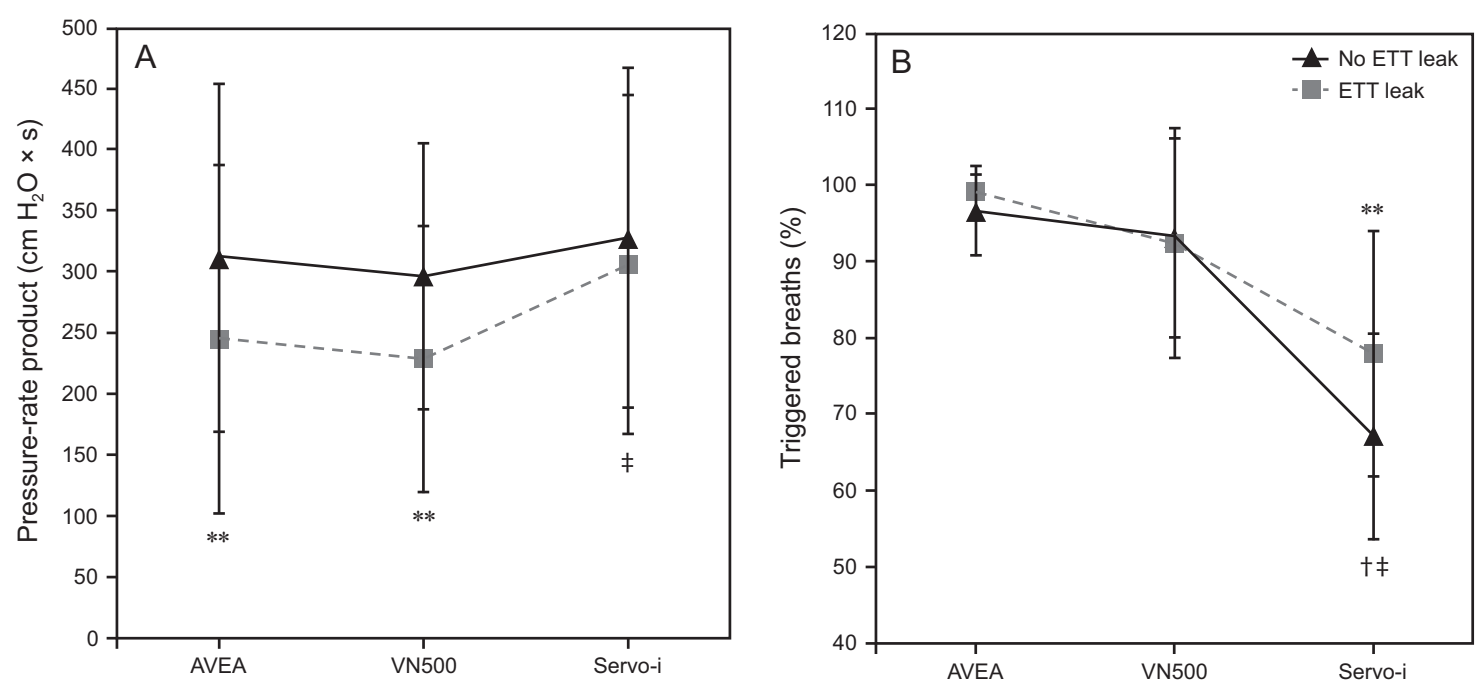

Fig. 3. Effect of each ventilator's volume-targeted mode with and without ETT leak on pressure-rate product (A) and percentage of triggered breaths (B). Data are presented as mean \pm SD for $45 \mathrm{~s}$ of recorded data. Linear-mixed effects model was used to evaluate the association of ventilator and leak status on each continuous outcome variable, with ventilator type and leak status treated as fixed effects; $P<.05$ was considered significant: $† P<.05$ between the AVEA and Servo-i within leak and no leak conditions; $\ddagger P<.05$ between the Babylog VN500 and Servo-i within leak and no leak conditions; ${ }^{* *} P<.05$ between leak and no leak conditions within the ventilator brand.
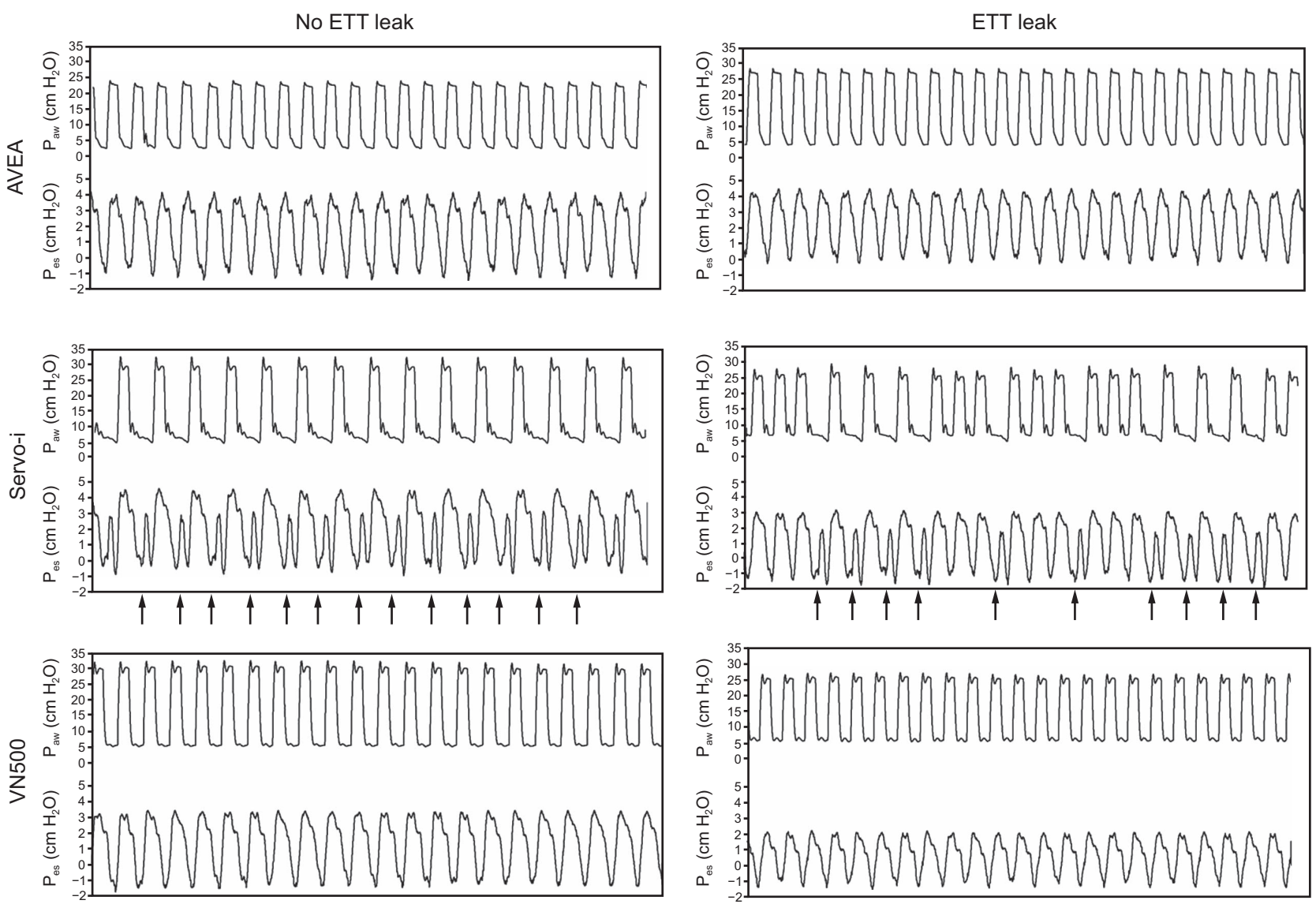

Fig. 4. Airway (upper) and esophageal (lower) pressure (in $\mathrm{cm} \mathrm{H}_{2} \mathrm{O}$ ) recorded over a 15-s period in one animal. The arrows represent the efforts being made without a corresponding ventilator-assisted breathe being delivered. 


\section{Volume-TARgeted Ventilation IN RABbits}

Graphic PIP and esophageal pressure waveforms in one animal, which was representative of most animals, and highlighted differences in trigger efforts among ventilator brands and leak conditions are shown in Figure 4.

\section{Discussion}

To our knowledge, these were the first physiologic data by using a spontaneously breathing animal model of surfactant-deficiency and respiratory distress syndrome to show associations between specific volume-targeted modes across ETT leak and non-leak conditions. The major finding of this study was that different volume-targeted modes may exhibit different levels of ventilator assistance and respiratory support under specific conditions. All 3 of the different volume-targeted modes supported oxygenation and ventilation similarly in a juvenile rabbit model of severe respiratory distress syndrome when there was no ETT leak. Because uncuffed ETTs are frequently used in neonatal patients, ETT leak is a common occurrence in the neonatal ICU setting, and this may result in the need for reintubation to upsize the tube, especially when ventilator volume-targeted modes are not able to provide adequate support. Based on our findings in the scenario of a moderate ETT leak, the volume-guarantee option on the AVEA and Babylog VN500 were able to provide a greater PIP and number of ventilator-supported breaths, which resulted in lower $\mathrm{P}_{\mathrm{aCO}_{2}}$ and higher $\mathrm{pH}$ than did the pressure-regulated volume control (PRVC) mode on the Servo-i ventilator.

We speculated that a primary reason why the AVEA and Babylog VN500 were able to provide greater support with an ETT leak is related to the fact that $\mathrm{V}_{\mathrm{T}}$ and flow measurements at the proximal airway are used to achieve the target $\mathrm{V}_{\mathrm{T}}$ and provide flow triggering, respectively. Also, because these ventilators adjust PIP based on either expiratory or an adaptive leak corrected $\mathrm{V}_{\mathrm{T}}$, both ventilators are capable of compensating for volume loss to the atmosphere through moderately sized ETT leaks and will increase PIP to achieve the pre-set $\mathrm{V}_{\mathrm{T}}$. As such, we speculated that the lower observed $\mathrm{P}_{\mathrm{aCO}}$ and higher $\mathrm{pH}$, with the AVEA and Babylog VN500 volume-guarantee modes may be a direct result of $\mathrm{CO}_{2}$ being purged from the tracheal dead space to the atmosphere through the ETT leak as PIP increases.

Also, because these volume-guarantee modes add additional flow to maintain PEEP and triggering (expiratory leak compensation), this additional flow may reduce the amount of inspired $\mathrm{CO}_{2}$ during exhalation, which may further improve ventilation when an ETT leak is present. Similar mechanisms of gas exchange have been described with increasing flows and pressure when using heated highflow nasal cannula. ${ }^{14-16}$ This study was not only the first to show differences in short-term physiologic outcomes be- tween leak and no ETT leak conditions but also that there may be a clinical benefit to having an ETT leak (higher $\mathrm{pH}$ and lower pressure-rate product) but only when using modes that apply adaptive leak compensation algorithms. Additional studies are needed to determine if fewer patients may need to be reintubated with a larger-sized ETT for clinical deterioration when selecting these modes over others that are not leak compensated.

As mentioned previously, the Servo-i PRVC mode differs from the other 2 ventilators in that it uses the inspiratory $\mathrm{V}_{\mathrm{T}}$ measurement acquired back at the ventilator in its algorithm to adjust PIP levels to achieve goal $\mathrm{V}_{\mathrm{T}}$ during volume-targeted ventilation. The Servo-i has a proprietary disposable pneumotachometer that can be placed at the proximal airway to measure $\mathrm{V}_{\mathrm{T}}$ and flow; however, these values are not used to guide the PRVC algorithm or assist with inspiratory-flow triggering. ${ }^{17}$ Also, a circuit compliance compensation calculation is used to estimate $\mathrm{V}_{\mathrm{T}}$ and account for any compressible volume loss in the circuit. Circuit compliance compensation has been shown to improve the accuracy and precision of ventilator-displayed $\mathrm{V}_{\mathrm{T}}$ when compared with having no circuit compliance compensation. ${ }^{18}$

However, this calculation has also been shown to result in underestimation of delivered $\mathrm{V}_{\mathrm{T}}$ with PRVC: ventilator displayed (estimated) values were $(\sim 1 \mathrm{~mL} / \mathrm{kg})$ lower than those actually measured when using a research pneumotachometer placed at the proximal airway in infants $\geq 2 \mathrm{~kg} .{ }^{18}$ The observed reduction in $\mathrm{V}_{\mathrm{T}}$ with an ETT leak may be due, in part, to inadvertent weaning of PIP but also could be related to how $\mathrm{V}_{\mathrm{T}}$ delivery is estimated based on the tubing compliance calculation and ability to properly measure for ETT leak, which resulted in $\sim 1 \mathrm{~mL} / \mathrm{kg}$ less $\mathrm{V}_{\mathrm{T}}$ delivery than the other ventilators. Nonetheless, similar to our findings in animals, relatively small changes in delivered $\mathrm{V}_{\mathrm{T}}(\sim 1 \mathrm{~mL} / \mathrm{kg})$ and PIP during volume-targeted ventilation have been shown to result in clinically relevant differences in work of breathing, ${ }^{19}$ minute ventilation and $\mathrm{CO}_{2}$ production ${ }^{20}$ in human premature infants.

It is unclear how effective the circuit compliance calculation with the Servo-i can be in low birthweight infants, especially with an ETT leak, but, based on our findings in animals, there was a $14 \%$ difference in accuracy between the ventilator-displayed $\mathrm{V}_{\mathrm{T}}$ and the delivered $\mathrm{V}_{\mathrm{T}}$, with a $50 \%$ simulated leak. As such, the major limitation of the PRVC mode with an ETT leak is that using $\mathrm{V}_{\mathrm{T}}$ delivery and compliance is overestimated, which may lead to undesirable reductions in PIP, which may also result in hypercapnia and lung de-recruitment. ${ }^{1}$ In addition to poor triggering, we postulated that inadvertent PIP reduction was also a major reason why animals had lower minute ventilation and greater respiratory distress when using the Servo-i. 


\section{Volume-TARgeted Ventilation IN RABbits}

Conversely, a similar argument can be made that there are limitations on how the AVEA volume-guarantee mode uses exhaled $V_{T}$ to guide PIP, which may underestimate the actual $\mathrm{V}_{\mathrm{T}}$ delivery to the lungs and provide excessive $V_{T}$ with an ETT leak. This excessive $V_{T}$ delivery may lead to hypocarbia and air leak. ${ }^{21}$ In fact, we did note higher $\mathrm{V}_{\mathrm{T}}$ delivery and lower $\mathrm{P}_{\mathrm{aCO}}$ values, along with consistent ventilation at the high pressure limit setting $\left(30 \mathrm{~cm} \mathrm{H}_{2} \mathrm{O}\right.$ with audible alarms) in many cases with the AVEA after an ETT leak. However, these values were not concerning because both the AVEA and Babylog VN500 have an integrated volume-limit feature that will terminate breath delivery when measured inspiratory $\mathrm{V}_{\mathrm{T}}>130 \%$ of the set $\mathrm{V}_{\mathrm{T}}$. With the Babylog VN500, these problems have been reduced because the volume-guarantee assist-control mode adjusts PIP based on a $\mathrm{V}_{\mathrm{T}}$ that is estimated and compensated for based on the magnitude of the calculated inspiratory and expiratory leak. ${ }^{21}$

Our findings were an extension of a previous study that also showed variable performance among different ventilator brands' volume-targeted modes in simulated neonatal lung models (500-4,000 g) with different ETT leak conditions (0-100\%). ${ }^{4}$ The Servo-i, AVEA, and Babylog VN500 were used in assist control with proprietary proximal flow sensors and modes similar to our study. The Babylog VN500 and AVEA had acceptable $V_{T}$ within $10 \%$ of the goal $V_{T}$, and the Servo-i PRVC $V_{T}$ was $\geq 10 \%$ in most of the test conditions without an ETT leak. After implementation of the ETT leak, $\mathrm{V}_{\mathrm{T}}$ within the lung model was not able to be measured accurately due to an inability of the lung model to effectively trigger a minimum of 5 consecutive breaths with the Servo-i PRVC mode. Unlike our findings, the AVEA volume-guarantee mode was shown to consistently deliver excessive $\mathrm{V}_{\mathrm{T}}$ after the ETT leak ( $\sim 123-137 \%$ of the set $\mathrm{V}_{\mathrm{T}}$, depending on patient size). It is interesting to note that, similar to our findings, the Babylog VN500 was one of the only ventilators to have minimal effects in delivered $\mathrm{V}_{\mathrm{T}}$ (within $10 \%$ of the pre-set value) in all testing conditions, including 50 and $100 \%$ leak conditions. Another study reaffirms the importance of proximal $\mathrm{V}_{\mathrm{T}}$ monitoring location for accurate $\mathrm{V}_{\mathrm{T}}$ delivery with ETT leak in infants with low lung compliance. ${ }^{22}$

Although short-term studies evaluating patient-ventilator interaction are lacking in premature infants, there are 2 phenomena related to triggering that may contribute to poor gas exchange and asynchrony. These include: (1) an inability of the ventilator to sufficiently detect a flow or pressure signal when a patient inspiratory effort is made, and (2) auto-triggering when an ETT leak is present. In the past, an inability to provide patient-synchronized ventilation was associated with major consequences and often required muscle paralysis and heavy sedation, and was associated with prolonged respiratory support. ${ }^{23}$ Synchronized or "patient- triggered" ventilation, according to a meta-analysis, has been shown to result in a trend toward a shorter duration of mechanical ventilation than non-patient-triggered ventilation in premature infants. ${ }^{24}$

We noted that triggering was more successful in our animal model when flow input for triggering was measured in the proximal airway and when using a mode that provided expiratory leak compensation. Expiratory leak compensation algorithms may help with ETT leaks by adding flow during exhalation, which stabilizes the PEEP levels and provides a sufficient bias flow from which to flow trigger breaths when respiratory efforts are being made. This was helpful in determining why AVEA and Babylog VN500 ventilators, which measure flow in the proximal airway with a flow sensor and have expiratory leak compensation capabilities, had $>90 \%$ successful breaths triggered by the animals with and without an ETT leak. This was different from the Servo-i PRVC mode, which had, at best, $\sim 60-78 \%$ of breaths successfully triggered. This may be due to a lack of expiratory leak compensation as well as the flow-triggering measurement located back at the ventilator.

We believed that minute ventilation was negatively impacted due to an inability of the animals to effectively trigger PRVC breaths from the Servo-i. This could be a major contributing reason why ventilation was compromised when the animals were supported with the Servo-i with and without a leak. In a previous study that used a spontaneously breathing lung model of a premature infant (1-2 kg) with respiratory distress syndrome, the Servo-i PRVC assist-control mode was shown to have greater asynchrony index than Babylog VN500 and AVEA volumeguarantee modes. ${ }^{4}$ Similar to our study, a major cause for asynchrony was related to ineffective efforts: respiratory efforts were not able to trigger a ventilator breath.

We observed that animals frequently made 2 inspiratory efforts before a breath could be triggered in PRVC with the Servo-i (Fig. 4). An increased caloric expenditure might explain why $\mathrm{CO}_{2}$ levels were generally higher and $\mathrm{pH}$ lower than with the AVEA and Babylog VN500. However, it is interesting to note that triggering did improve with the Servo-i after the ETT leak. We speculated that the presence of a leak actually benefited the signal-tonoise ratio of the patient flow because the flow sensor at the ventilator was no longer required to measure near-zero flow, thus, all flows measured by the Servo-i may be biased by the ETT leak. Future ventilator improvements are needed to reduce ventilator response times and improve triggering because these may contribute to ventilator asynchrony, ${ }^{25}$ which leads to negative outcomes, including prolonged intubation, ${ }^{26,27}$ increased sedative use, ${ }^{28-30}$ and higher mortality. ${ }^{31}$ 


\section{Volume-TARgeted Ventilation IN RABbits}

\section{Limitations}

The major limitations of the present study derived from the use of an animal model with different pulmonary anatomies than are found in prematurely born human infants, along with mature lung structure undergoing active surfactant metabolism. This limited the ability of the lavage procedure to provide a stable surfactant-deficient model, which, in turn, limited our ability to study the long-term effects of the different modes of respiratory support studied. This was why we randomized the mode and leak order, and were only able to study short-term physiologic outcomes. Because the study was short term and the animals served as their own controls, we could not study any major complications (ie, lung injury and/or inflammation) related to mode operation and prematurity. Also, because these animals were relatively small $(\sim 1.6 \mathrm{~kg})$, sedated, and had severe lung disease (similar to infant respiratory distress syndrome), it was difficult to extrapolate from these animal findings and expect similar results in human newborns, especially if they are larger, have a milder form of lung disease, or are not sedated.

We used a research pneumotachometer in series with each of the testing conditions. This may have added some dead space and resistance, and inversely impacted some physiologic measurements. However, we attempted to overcome these deleterious effects by using a flow sensor with extremely low dead space and resistance as well as increased the pre-set $\mathrm{V}_{\mathrm{T}}$ to overcome any issues related to compressible volume loss that resulted in hypoventilation.

It should be noted that we chose to evaluate performance beyond some manufacturers' recommendations, similar to previous bench studies. ${ }^{4}$ We evaluated the Servo-i PRVC ventilator mode with a moderately sized ETT leak $(50 \%)$. The Servo-i ventilator operator's pocket guide ${ }^{32}$ notes the following: "PRVC mode of ventilation is not recommended when a patient has leakage; which usually occurs around the endotracheal tube." However, because an ETT leak is extremely prevalent in the neonatal ICU setting, it is unclear whether small-to-moderately sized ETTs leaks would affect pressure delivery and ventilation with this ventilator.

It is also important to note that, after the completion of this experiment, a newer generation of the Servo ventilator (Servo-U) ventilator received $510(\mathrm{~K})$ clearance from the FDA with PRVC. This ventilator has had several technologic enhancements, including the following: (1) proximal hotwire flow sensor for measuring and targeting $\mathrm{V}_{\mathrm{T}}$ and for triggering, and (2) the ability to provide leak compensation during inhalation-exhalation with ETT leaks up to $60 \%$. As such, it is important to not extrapolate findings from the current study with the Servo-i PRVC mode and assume a similar performance with the Servo U ventilator. Future studies are needed to determine if there are phys- iologic differences related to ventilator performance between PRVC modes offered with these 2 ventilators.

\section{Clinical Implications}

Increased work of breathing and poor gas exchange are 2 important clinical factors that may contribute to respiratory failure and the ongoing need for mechanical ventilation in premature infants. Differences in ventilator brands' performance and the ability to appropriately deliver $\mathrm{V}_{\mathrm{T}}$ and PIP, and allow effective triggering with volume-targeted ventilation may have several important clinical implications in the pre-term neonatal patient population. The Servo-i uses inspiratory $\mathrm{V}_{\mathrm{T}}$ and provides triggering and $\mathrm{V}_{\mathrm{T}}$ measurements based on values acquired back at the ventilator and not proximal to the patient, as with the other ventilators, during volume-targeted ventilation. Also, unlike the other ventilators, the Servo-i targets a calculated inspired $\mathrm{V}_{\mathrm{T}}$ (based on tubing compliance) and not expiratory or adaptive leak-compensated $\mathrm{V}_{\mathrm{T}}$, thus, it is likely that combined inadequate triggering and reduced PIP with an ETT leak condition were major contributing factors that explained some of the observed differences in minute ventilation, the effort of breathing (pressure-rate product), and gas exchange between the Servo-i and the other ventilators tested.

\section{Conclusions}

Based on our observations, we believed that clinical success and future research of volume-targeted modes in neonates should use ventilators with algorithms that incorporate expiratory $\mathrm{V}_{\mathrm{T}}$ or leak-corrected $\mathrm{V}_{\mathrm{T}}$ measured at the proximal airway because these ventilators may deliver better ventilation support by compensating for the leak of air around an ETT.

\section{REFERENCES}

1. Claure N, Bancalari E. Methods and evidence on volume-targeted ventilation in preterm infants. Curr Opin Pediatr 2008;20(2):125131.

2. Klingenberg C, Wheeler KI, McCallion N, Morley CJ, Davis PG. Volume-targeted versus pressure-limited ventilation in neonates. Cochrane Database Syst Rev 2017;10:CD003666.

3. Klingenberg C, Wheeler KI, Owen LS, Kaaresen PI, Davis PG. An international survey of volume-targeted neonatal ventilation. Arch Dis Child Fetal Neonatal Ed 2011;96(2):F146-F148.

4. Itagaki T, Bennett DJ, Chenelle CT, Fisher DF, Kacmarek RM. Performance of leak compensation in all-age ICU ventilators during volume-targeted neonatal ventilation: A lung model study. Respir Care 2017;62(1):10-21.

5. Baydur A, Behrakis PK, Zin WA, Jaeger M, Milic-Emili J. A simple method for assessing the validity of the esophageal balloon technique. Am Rev Respir Dis 1982;126(5):788-791.

6. Ross PA, Hammer J, Khemani R, Klein M, Newth CJ. Pressure-rate product and phase angle as measures of acute inspiratory upper 


\section{Volume-TARgeted Ventilation IN RABbits}

airway obstruction in rhesus monkeys. Pediatr Pulmonol 2010;45(7): 639-644.

7. Diblasi RM, Zignego JC, Tang DM, Hildebrandt J, Smith CV, Hansen TN, Richardson CP. Noninvasive respiratory support of juvenile rabbits by high-amplitude bubble continuous positive airway pressure. Pediatr Res 2010;67(6):624-629.

8. Argent AC, Hatherill M, Newth CJ, Klein M. The effect of epinephrine by nebulization on measures of airway obstruction in patients with acute severe croup. Intensive Care Med 2008;34(1):138-147.

9. Argent AC, Newth CJ, Klein M. The mechanics of breathing in children with acute severe croup. Intensive Care Med 2008;34(2): 324-332.

10. Khemani RG, Hotz J, Morzov R, Flink R, Kamerkar A, Ross PA, Newth CJ. Evaluating risk factors for pediatric post-extubation upper airway obstruction using a physiology-based tool. Am J Respir Crit Care Med 2016;193(2):198-209.

11. Khemani RG, Hotz J, Morzov R, Flink RC, Kamerkar A, LaFortune $\mathrm{M}$, et al. Pediatric extubation readiness tests should not use pressure support. Intensive Care Med 2016;42(8):1214-1222.

12. DiBlasi RM, Crotwell DN, Poli J, Hotz J, Cogen JD, Carter E. A pilot study to assess short-term physiologic outcomes of transitioning infants with severe bronchopulmonary dysplasia from ICU to two subacute ventilators. Can J Respir Ther 2018;54(1):1-6.

13. McCullagh P, Nelder JA. Generalized linear models. 2nd edition. London, UK: Chapman \& Hall/CRC Press; 1989.

14. Möller W, Celik G, Feng S, Bartenstein P, Meyer G, Oliver E, et al. Nasal high flow clears anatomical dead space in upper airway models. J Appl Physiol (1985) 2015;118(12):1525-1532.

15. Nielsen KR, Ellington LE, Gray AJ, Stanberry LI, Smith LS, DiBlasi RM. Effect of high-flow nasal cannula on expiratory pressure and ventilation in infant, pediatric, and adult models. Respir Care 2018; 63(2):147-157.

16. Frizzola M, Miller TL, Rodriguez ME, Zhu Y, Rojas J, Hesek A, et al. High-flow nasal cannula: impact on oxygenation and ventilation in an acute lung injury model. Pediatr Pulmonol 2011;46(1):67-74.

17. Chatburn RL, Carlo WA. Description of available devices. In: Goldsmith JP, Karotkin EH, Keszler M, Suresh GK, editors. Assisted ventilation of the neonate. 6th edition. Philadelphia, PA: 2017;251274.

18. Heulitt MJ, Thurman TL, Holt SJ, Jo CH, Simpson P. Reliability of displayed tidal volume in infants and children during dual-controlled ventilation. Pediatric Crit Care Med 2009;10(6):661-667.

19. Patel DS, Sharma A, Prendergast M, Rafferty GF, Greenough A. Work of breathing and different levels of volume-targeted ventilation. Pediatrics 2009;123(4):e679-e684.
20. Herrera CM, Gerhardt T, Claure N, Everett R, Musante G, Thomas C, Bancalari E. Effects of volume-guaranteed synchronized intermittent mandatory ventilation in preterm infants recovering from respiratory failure. Pediatrics 2002;110(3):529-533.

21. Keszler M, Morley CJ. Tidal volume-targeted ventilation. In: Goldsmith JP, Karotkin EH, Keszler M, Suresh GK, editors. Assisted ventilation of the neonate. 6th edition. Elsevier; Philadelphia, PA: 2017;195-204.

22. Al-Majed SI, Thompson JE, Watson KF, Randolph AG. Effect of lung compliance and endotracheal tube leakage on measurement of tidal volume. Critical Care 2004;8(6):R398-R402.

23. Keszler M, Mammel MC. Basic modes of synchronized ventilation. In: Goldsmith JP, Karotkin EH, Keszler M, Suresh GK, editors. Assisted ventilation of the neonate. 6th edition. Elsevier; Philadelphia, PA: 2017;180-204

24. Greenough A, Rossor TE, Sundaresan A, Murthy V, Milner AD. Synchronized mechanical ventilation for respiratory support in newborn infants. Cochrane Database Syst Rev 2016;9:CD000456.

25. Kondili E, Prinianakis G, Georgopoulos D. Subject-ventilator interaction. Br J Anaesthesiol 2003;91(1):106-119.

26. Thille AW, Rodriguez P, Cabello B, Lellouche F, Brochard L. Subject-ventilator asynchrony during assisted mechanical ventilation. Intensive Care Med 2006;32(10):1515-1522.

27. de Wit M, Miller KB, Green DA, Ostman HE, Gennings C, Epstein SK. Ineffective triggering predicts increased duration of mechanical ventilation. Crit Care Med 2009;37(10):2740-2745.

28. Hansen-Flaschen JH, Brazinsky S, Basile C, Lanken PN. Use of sedating drugs and neuromuscular blocking agents in subjects requiring mechanical ventilation for respiratory failure. A national survey. JAMA 1991;266(20):2870-2875.

29. de Wit M, Pedram S, Best AM, Epstein SK. Observational study of subject-ventilator asynchrony and relationship to sedation level. J Crit Care 2009;24(1):74-80.

30. Shehabi Y, Chan L, Kadiman S, Alias A, Ismail WN, Tan MA, et al.; Sedation Practice in Intensive Care Evaluation (SPICE) Study Group investigator. Sedation depth and long-term mortality in mechanically ventilated critically ill adults: A prospective longitudinal multicenter cohort study. Intensive Care Med 2013;39(5):910-918.

31. Blanch L, Villagra A, Sales B, Montanya J, Lucangelo U, Luján M, et al. Asynchronies during mechanical ventilation are associated with mortality. Intensive Care Med 2015;41(4):633-641.

32. Maquet. Servo-i ventilator pocket guide: ventilation, Servo-i v. 3.0, ventilation of neonates and pediatrics. Maquet; Solna, Sweden: 2015

This article is approved for Continuing Respiratory Care Education credit. For information and to obtain your CRCE

(free to AARC members) visit

www.rcjournal.com

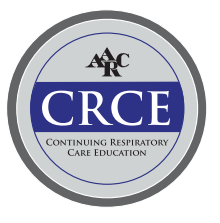

